\title{
Esports and the Color Line: Labor, Skill, and the Exclusion of Black Players
}

\author{
Akil Fletcher \\ National Science Foundation (GRFP) \\ University of California, Irvine \\ Affletch@uci.edu
}

\begin{abstract}
This article focuses on the exclusion of black players from PC esports through constructed forms of skill and labor. While esports is one of the fastestgrowing industries in America, it remains an overwhelmingly white and Asian field. Thus, this piece explores the absence of black players by examining profit, labor, and blackness to analyze the devaluing of the black body and why it has been rendered valueless in the space of PC esports. In doing so, I provide an analysis of skill and the ways in which merit helps to silence discussions on diversity, in order to provide a piece which serves as a questioning of the esports status quo. Additionally, this piece grapples with the many ways in which players come to envision themselves as both product and laborer in relation to the dearth of black PC esports players. This material is based upon work supported by the National Science Foundation Graduate Research Fellowship Program.
\end{abstract}

\section{Introduction}

In May 2016, Terrence Miller, a black Hearthstone player competing in Dreamhack Austin (a large competitive esports tournament event), was victim to one of the most infamous attacks of racism in recent esports history [14]. When Austin took the stage to start his match of Hearthstone (a competitive card playing game), the stream broadcasting his play exploded with racial slurs and the spamming of the "try hard emoji" (an image of a black face co-opted to serve as the white symbol for black gamers). Unsurprisingly, the story blew up and was featured on almost every popular gaming website in one form or another. Many renounced the behavior calling it despicable and vile and this repudiation would result in both Blizzard (the parent company of Hearthstone) and Twitch (the streaming service) vowing to do their best to make sure that it would never happen again. It was an event that prompted a deep visceral response from both players and companies, as everyone scrambled to put out the fires that came with such blatant racism.

My goal in this paper is to show how this event can be understood in the broader context of race in contemporary esports. Looking at recent history, events like the outrage towards the story of Mortal Kombat's Jax, racist reenactments of lynching on the online game Red Dead Redemption 2, and \#Gamergate all point to ongoing issues of diversity and race within gaming. Miller's case then, was just one of the many instances of discrimination in a space which has been rife with issues. Miller's interaction was notable for two reasons. First, it was made visible in the moment through the power of streaming. Second - and most importantly-it happened within the upper echelons of high-level competitive gaming. The U.S PC esports scene suffers from a major lack of diversity, in which most of the professional player base is almost entirely white or Asian males. This means that not only was Miller's harassment egregious, it was also rare for the simple fact that there are not a lot of black professional players to begin with. This is key in understanding the event because while Miller's story is indeed tragic, it does reveal the simple truth that there is a major lack of diversity within PC esports. But the question remains, why?

While this event does portray some of the more toxic reasons behind the dearth of black players, in this article I will explore ways in which there is more at work than a simple act of online racism. I conclude the lack of black PC professional players cannot simply be attributed to a toxic space or environment. And, while there are no simple answers, I believe Miller's case serves as an opportunity to engage with the many possibilities which may lead to such scarcities. Within the turbulence of this racist story there lies a golden opportunity to engage with questions of labor, merit, and accessibility which plague many black players today. For this reason, rather than providing simple answers to a 
complicated issue my goal throughout this piece is to shed light on a few of the issues which may contribute to the missing black professional PC player base. By engaging with scholars such as Lisa Nakamura, Tanner Higgins, Harvey Young, and Kishonna Gray, I hope to further the analysis of how black players (professional and those aspiring to be) are excluded from professional PC gaming.

\section{Gaming, Race, and Labor}

Gaming can operate as a form of leisure, therapy, or communication, and at times all of these things at once. However, recently there has been much attention given to whether gaming can be classified as a form of labor. After all, how could a video game (something typically designed to be fun and enjoyable) be a form of work? Yet, with the recent rise of esports and a fecund digital media industry, many have begun to question whether games should be considered a form of labor. Quite often there is no dispute around whether or not those who create and maintain games are meticulous workers, since they provide or help to provide a material product which is sold and bought like any other; however, issues arise when there is discussion to be had regarding those who engage with a game's content. Are they merely "consumers" and "users?" In what ways are they engaged in forms of labor and production? And, where does this leave the consumer of a product thought to have already been "consumed"? Questions like this pop up throughout the industry and point to the incongruence of gaming work and previous ideas of labor as producers such as streamers, writers, and particularly professional gamers are often misconstrued to be playing, rather than working. While these claims hold little weight under the scrutiny of scholars such as T.L Taylor, who in her book Raising the Stakes, makes clear that there is a tremendous amount of both physical and emotional labor which goes into both playing and being a fan of a game, there is an undeniable dissonance between the gaming sphere and how we define labor [17]. For a key example look no further than the esports industry, a perfect maelstrom of this very dissonance. Where players, teams, and companies are all caught between transforming definitions of labor and capital, and where esports, like any other capitalist venture, is driven by the goal of profit.

In capitalism, profit typically comes through some form of labor exploitation. Within a neoliberal capitalist imagination labor is often denoted by what generates profit, and unsurprisingly it is this need for profit which defines and drives the trends of the esports industry. As Karl Marx writes in "Chapter 15 of Capital, Vol. 1 alongside to lengthening the working day and compelling workers to labor harder, technology allows capitalists to produce surplus value and thereby profit at the worker's expense" [2]. While Marx could not have foreseen the scale in which we use technology today there is a prophetic bent to his words as the technology of games has become both the lifeline, and the key tool in the exploitation of the esports player. In this way players are caught between an intersection of play and work as they come to be defined by a larger conversation of gaming and an industry need to create and shore up revenue. Through, Marx it becomes visible that the definitions of labor within esports have become inextricable from that of profit, because while games may not be the industrial machines of his day they are the technology which provide the esports industry the ability to exploit the worker, simultaneously locking the player to an identity which is profitable. However, there is a cost to this thinking because as the identity of the player becomes bound and rigid to this idea of capital and the bodies which can provide such, there takes place an undeniable form of exclusion for those who cannot. After all, what happens when a player cannot provide capital value? Or, when a player of equal skill can no longer create revenue? The bounding of an esports identity to that which creates profit has inadvertently laid the groundwork to recreate many of the discriminatory biases and practices we see in other industries. This is because when all that matters is profit, issues such as race, gender, and sex will often remain as an afterthought.

It is here where I wish to invoke the writing of legal and race scholar Kimberlé Crenshaw and her work on intersectionality. For the relationship between race, gender and sex cannot be understated in the defining of a "profitable body". This is because while this piece focuses heavily on one aspect of discrimination (race), it cannot be separated from the fact that esports and gaming spaces are inherently white/Asian, male, and mid to upper class dominated. For this reason, it is imperative to acknowledge the connected intricacies of this research lest it fall prey to the short comings of having too narrow a scope. It is this very fear Crenshaw brings to our attention with her writings on the disappearance of black women from the theoretical scope of feminism where she writes: "this focus on the most privileged group members marginalizes those who are multiplyburdened and obscures claims that cannot be understood as resulting from discrete sources of discrimination" [4]. Put simply, a focus on class alone cannot explain the phenomena in which bodies 
are made profitable and it is for this reason intersectionality must be employed.

This becomes key to my argument as critical race scholarship has long pointed to the fact that the bodies of people of color have long been connected to their ability to create profit. Using an example from Lisa Nakamura's article Indigenous Circuits, this is easy to see as she points out that the inherent value of Navajo workers was derived from their ability to provide quick and efficient labor in constructing microchips in a rush for globalization. While not entirely analogous to the black experience in gaming and esports this is worth mentioning because of the ways the factory owners within the article point to the "intrinsic ability", and strong work ethic of Navajo women. "The notion that Indians were 'inherently flexible' both racialized and preceded the idea of flexible labor" [15]. In this way an identity of labor and use was created to explain the exploitation of a group of people mistakenly thought to be primitive. A fact which bears stark resemblance to the ideas of black bodies being inherently made for, and not suitable for specific types of work. This is important because through intersectionality it becomes apparent that capital (and one's ability to produce such) is very much entangled into the many aspects of their identity and where certain bodies were exploited, other were turned away. Entirely focused on the idea of profit within a neoliberal age, the owners of companies like Fairchild created a use for people who were deemed by the American conscious to be "underused", and there has been a similar transformation of the black body throughout a history of exploitation. For blackness has been entangled in a history of colonialism and slavery which sought to extract profit from black labor.

This cannot be ignored as capitalism is very much steeped within a history of black oppression: "every class relation at least bears traces and has certain features of slavery" [6]. It should come as no surprise then that such a foundational history exists in all facets of life, including those as ostensibly benign as esports. Yet, by this logic one would expect an abundance of black bodies. If capitalism functions and has been built upon black labor, why then has this labor been excluded from esports? Here lies the paradox of black labor in esports, for you see, while the disenfranchised have typically held a role of being exploited for their labor, their value has been equally determined both by what they could do, and by what they could not. As Patricia Hill Collins points out, "the subject/object gain their meaning only in relation to their difference from their oppositional counterparts [7]. Put simply, black value has come to be derived equally from its barring, as the exclusion of blackness marks a space in which whiteness remains the unchallenged default. However, let me be clear, this is not to say that gaming and esports industries are recreating facets of slavery, I am simply stating that in the defining of a body which is profitable, there is undeniably a connection to the ways we have come to define and interact with labor, capital, and the black body in a system of neoliberal capitalism. This then means that the value of the black body, even within esports, is shaped by neoliberal logics which seeks only to extract value, and this is one of the very reasons why black bodies are virtually absent from PC esports. For you see if the black body is not profitable, then it becomes unnecessary in the industry of esports. While, this may seem contradictory to the typical logics of black labor extraction, it is important to note that black absence, even inadvertently, is just as profitable.

In my gesturing towards the black body it is important to note that I do not simply mean the physical. Blackness is not something that is merely corporeal but is at the same time something cultural, social, and abstract. Within the confines of capitalism, the constructions of what is perceived to be blackness or "black" can be just as real as the flesh itself. Building upon Fanon, Harvey Young make us privy to this by writing: "when popular connotations of blackness are mapped across or internalized within black people, the result is the creation of the black body. This second body, an abstracted and imagined figure, shadows or doubles the real one. It is the black body and not a particular, flesh-and-blood body that is the target of a racializing projection" [20]. Thus, the exclusion of black bodies or more specifically black players from esports is not just an exclusion of the physical but of the very notion of blackness itself. In doing this, the profitable esports body is demarcated by lines of color which solidify the walls of exclusion.

However, while the relationship between black people and emergent technologies within the U.S have not always been altruistic, I do not believe that the PC esports industry is deliberately choosing to exclude black players. After all, the Fighting Game Community (FGC) has an abundance of black and brown players, most notably Dominique McLean or "Sonic Fox" who was named ESPN's 2018 esports player of the year. However, deliberate or not there is an undeniable shaping of a PC esports identity which while not actively excluding black players, does little to bring them into the fold. This is because while black players could possibly bring revenue into the $\mathrm{PC}$ esports scene, it is by far more profitable (at this point) to maintain the status quo. There are both 
structural and cultural barriers such as the high cost of gaming PC systems, the lack of public facilities, and the issue that PC gaming suffers from a stigma of being an exclusively white and Asian space [18]. But there is often the overlooked aspect of whose labor gets valued even when that labor, is a labor of play.

\section{Meritocracy and Race}

While I have discussed the aspects of labor and industry which have come to devalue the presence of black players in esports, I feel it necessary to discuss the many ways in which this cycle is perpetuated. For you see, up until now I have been writing towards the neoliberal logics which guide the industry today, but, profit and exploitation while salient, cannot explain the dearth of prominent black figures alone. After all, it is this very focus on profit which serves to recreate these rigid identities and while I find it important to critique these mechanisms of capitalism, I do not want to lock them into rigid theory and definition. Thus, I wish to build upon my previous argument by transitioning into the second aspect of this piece, merit and skill. There has been much work done on both the topics of merit and meritocracy since its original usage in the work of Michael Young's The Rise of Meritocracy [1]. And, while much of the work covers broad topics there is value in analyzing this trend in consideration of esports and gaming. Building upon the work of Stephen J. McNamee and Robert K. Millers Jr's The Meritocracy Myth I wish to make an argument for the ways in which merit and by extension skill come to shape the logics of players and esports. Within the work both authors take great care to describe how the American consciousness has come to be shaped by ideas of the American dream and merit. Stating that "the popular perception in America is that those who are made of the right stuff are the cream of the crop that rises to the top, whereas the dregs fall to the bottom" and there is an analogous belief within esports [13].

This popular myth made vogue since the "rags to riches" stories of Horatio Alger (and likely long before) has come to reappear within the esports milieu like a bad rash [21]. Take again, Miller's Hearthstone case which was an undeniable indication of racism in the industry, yet there are still those who claim there is no such issue, as the realm of professional esports is not one dominated by race, but instead by the laws of merit and skill. Put simply, in the supposed colorblind world of gaming, professionals are not chosen by color but instead by skill. "Skill" comes to function not just as a tool of measure, but as a means to ensure unbiased play. For in theory, skill is meant to operate as the great equalizer, providing everyone an "equal" opportunity to make it big. However, like labor, "skill" hardly functions as just a means to decide who is and is not worthy of being a pro. More often than not, "skill" like merit is a wrapping of social and economic practices which, while requiring a player to have the ability to play well, entails far more than just playing a game. For you see, it requires a large amount of time, money and resources to maintain the "skill" of a professional within the U.S. One's skill is not entirely dependent on one's work ethic or natural talents and is "heavily influenced by the resources and opportunities available" [13]. This is clear as many players who wish to become pro typically subject themselves to grueling practice routines where players like Elijah Galleger an Overwatch pro plays an average of 10 hours a day [10]. Additionally, since the recruitment of professional players is typically done through smaller tournaments and established social networks, "skill" is just as dependent on one's ability to navigate intricate social webs of teams, recruiters, and media coverage. In this way "skill" constitutes much more than just playing the game, as "skill" no longer functions as a simple meter for one's ability and instead comes to encompass the life and practices which go into being a pro. So, to claim one only needs skill to reach the pinnacle of professional gaming, is to ignore the many intricacies that makes such a task happen.

This leads directly into the issues of diversity in esports, as skill comes to be a powerful tool to silence those who speak out about diversity in esports. One's value within the community is often tied to their ability to play, thus skill can operate as powerful riposte to those who make complaints. This is not to say professionals are not skilled, nor am I arguing that we should lower the expectation for those at the competitive level. However, I am urging us to engage in how we define skill and realize what it helps to mask. For instance, the phrase "Git Gud", which simply functions as a taunt to those who lack skill, can be used as a statement to wave off those who worry about diversity within play. As legal scholar Anne Lawton points out "this focus on individual failings or in this case an inability to perform is at the centerpiece of the meritocracy myth" [12]. Thus, most conversation which attempts to point out the lack of diversity or any other societal issue is often negated by one's ability or inability to perform. Additionally, skill in the hands of less savory individuals can also serve as sanction for many to speak and perform in deleterious ways as one can feel emboldened (even entitled) to say and do anything they feel because they are good enough. In this way skill then becomes the currency through which 
players engage and one's opinions, contributions, and at times personhood is defined by such. However, the usage of skill is not all bad.

As a gamer, I know the value of being able to perform well within a game, especially since I and many other black players take pride in our ability to play videogames. After all, it is these very skills which function as a defense against the racism many of us experience within gaming, as what better way to prove you belong than to beat the players claiming you don't. This very phenomenon has in fact been pointed out within the work of Kishonna Gray where many of her own interlocutors found solace in knowing that their skill was enough to earn them a right to play, with one of her black lesbian interlocutors even going as far to say, "They can't beat me, they can't hurt me" [9]. For people of color a focus on skill can function as both a form of validation and resistance for many who feel inundated by seemingly endless waves of harassment. But, as powerful as this act is, skill can only do so much to assuage the discriminatory trends which plague esports. This is because "skill" comes to be racialized in association to those who are most apparent in esports, and this disavowal of race in favor of skill is another way blackness, and by extension black players are made invisible.

Tanner Higgins provides us with a powerful theoretical platform in which to analyze this through his article, Blackless Fantasy. In which by discussing the lack of black people and culture within Massive Multi-player online games, Higgins is able to provide key insight into how blackness becomes exiled. Within his article Higgins states "the omission of Black characters from the discourse devalues the potential of video games to provide productive racial experiences because they reinforce dominant notions of Blacks as incapable of being functional members of society [11]. In a similar fashion to games, the exclusion of Black players from esports both recreates and reinforces the boundaries which excluded them, and skill and labor are just two of these boundaries. For it is through this focus on specific types of skills and labor which we find the exclusion of black players. This culminates into my main argument as "skill" or an ability to play games is not missing. Rather, a call for skill is a means to block players who do not have access to the resources needed for both the game and the community around it. Git Gud then is at best a condemning of a player to assimilate to the specific cultures of a game and at worst a shaming for those who cannot access the resources necessary to assimilate in the first place.

\section{The Black Homo Oeconomicus and the Identity of a Player}

Throughout this piece I have gone to great lengths to build a theoretical foundation for the exclusion of black people in PC esports. By discussing the establishment of an esports labor identity which inadvertently excludes the black body due to its focus on profit and maintained by the implication of a specific form of skill-I have come to note just a few ways in which black players are kept from entering the professional PC esports scene. However, while there is much more to discuss pertaining these ideas, it is necessary to elaborate on how these conceptions come to form the black player. This is because while black players are excluded from the industry - they are still very much shaped by its practices. As Frantz Fanon made the realization of his racial multiplicity on that fated train ride so too, have many black players within gaming spaces come to realize the effects of their blackness [4]. While I have made clear in previous sections the ways in which the gaming industry and esports by extension have come to view the players through a neoliberal logic. I feel it necessary to now discuss the ways in which the players come to view themselves.

This is important as no one within a system simply sees themselves as a product of that system, and to claim such would be to reduce the beauty of freewill. Yet, at the same time one cannot ignore the ways in which these systems force us to change and adapt, and thus we must turn our attention directly to the player. But, how does one begin to explain the effects of such an intricate system? While, there is no easy way to do this, a productive place to begin would be through the examination of the ways in which players shape themselves amongst the capitalist logics. This is because while esports professionals are venerated for their skill and ability, they are consistently walking a tight rope of both laborer and product as they must simultaneously perform at a competitive level, while avoiding the precarities of digital labor. In this way, players must both conform and construct an identity which is both suitable and productive within the gaming scene and this can be seen heavily within the streaming practices of professionals as "streaming has become a critical component of a longer career, pointing out that the actual life of tournament competition is finite" [18]. In this way, a player must learn to build an "exploitable identity" lest they find themselves no longer needed in the grinding gears of the industry, and it is this fact which guides the construction of this identity. 
To further explore this, we may turn to the notion of "homo ocenomicus". Building off Foucault, Wendy Brown develops this term as: "when the neoliberal man comes to the market, 'being for himself his own capital, his own producer, the source of his earnings.' Whether he is selling, making, or consuming, he is investing in himself and producing his own satisfaction [3]. Homo oeconomicus then, is man made by neoliberal logics, a person by which value is derived through their own labor, and a person who is then exploitable through such labor. It is here where we begin to understand the mentality of professional players; as to survive in the industry players must become "homo oeconomicus suprema" or homo oeconomicus supreme. This is pointed out through the many ways in which professional players must remain relevant to their teams, fans, and games, and must contort themselves into the many forms the industry requires to remain prominent. By streaming, competing, practicing and living a life consumed by the world of gaming, players transform themselves into both a sellable product and a powerful producer.

There is an irony here that players who engage with material products are then made to be products themselves, but how does this selling of oneself come to shape the player, and more specifically how does it come to shape blackness? Illana Gershon points out that: "Under earlier forms of capitalism, according to MacPherson's 1962 account of possessive individualism, one understood one's relationship to oneself in terms of landed property-one owned one's self as though one's body and capacities could be treated metaphorically as property to be rented (in practice) as labor for certain amounts of time. As a consequence, the contract between employer and worker involved metaphorically leasing the body and its capacities for a certain period of time each day. By contrast, under neoliberal capitalism, one owns oneself as though one is a business, a collection of skills, assets, and alliances that must be continually maintained and enhanced".

This is a reality black people have known for far too long, as being black in a neoliberal society has often resulted in playing a constant game of catch up. What is consistently marked as the "standard" has often been made to be a constantly shifting bar in which black people are judged against. In this way, black individuals have consistently needed to adapt and change one's skillset (as Gershon points out) in order to survive in America, and thus have been rendered neoliberal bodies. To quote Lester $\mathrm{K}$. Spence, "we have always had to hustle" [16]. Through the creation of a black homo oeconomicus, black people have found new ways to both create and find purpose for their labor. And, while this is problematic in it of itself as conforming to western neoliberal ideologies often recreates the same structural issues, it is here where we see the final reason for the lack of black players in esports. This is because becoming profitable in one way does not guarantee success in other, and as stated before, because there is no value in black labor within esports, there is little reason for black people to join.

At issue here is that black people are more likely to engage and show interest in spaces which provide satisfaction and esteem. And, while the history of black labor displays many of us working in less than favorable environments, this comes often out of necessity. Thus, a space like PC esports which is already gated by high price, racist environments, and a conflation of work and play, esports can seems like a less than viable option. This is of course, not to say that black people do not love PC esports games, in fact, as Taylor points out from DiSalvo's, research "African and Hispanic American youth are more likely to play digital games than are Caucasian American youth" [17]. I am simply pointing out that in a space where there is little representation and the "skill" level, provides both a technical and socioeconomical barrier, there seems little chance that black players will succeed, or for that matter, would want too. This may also explain why the FGC has so much diversity, as not only is it significantly cheaper to gain access to this space, black players have also had a much better reception (although this is not saying much) within the FGC. And, while the FGC is a far more precarious esports industry with less sponsoring and smaller prize pools, it at least provides black players with an instance of small racial diversity despite its many faults of gender discrimination. Thus, if more black players are to be seen within the pc esports industry, there must be a reimagining of how we view both digital labor and blackness within such, only then may we find a resolution.

\section{Conclusion}

While I have conveyed that the lack of black players in esports is due to a complicated entanglement of capital and culture. I would be remiss if I did not mention that this additionally stems from the ways in which we view aspects of labor and play. While most forms of digital labor suffer from high levels of precarity, low unionization, and a belittlement that stems from the viewing of the digital or virtual, as less real. There, is undeniable an additional stigma placed upon the esports industry for their focus on play. This is of course, a rampant problem within the domain of most sports, as the line 
which defines work and play are tenuous at best. This battle of play/leisure and work adds an additional level of complexity to the industry. And, while my focus has been on this complexity in relations to black PC esports players, one cannot undermine the ways in which "play" has come to affect the ways in which we view both physical and esports labor. I mention this not to attach the digital to that of the physical, but to mark that there is both a historical and ideological connection in the ways we have engaged sports and labor.

Additionally, while my arguments have pushed for an examination of diversity (or the lack thereof) within esports. It is important to note that while diversity is important especially when it comes to aspects of representation, it is but one of the many issues at play when analyzing race and esports. Afterall, rarely has diversity alone solved the problem of racism and inequality, and quite often diversity is only achieved when people of color learn to play by the rulebook of those in charge, effectively changing very little [21]. This is a powerful implication which may very well serve as the impetus for future research but lies just at the periphery of the focus of this paper. Thus, in conclusion through my analysis of play, labor, skill, and identity I have provided but a few answers to an ongoing and prominent problem. There is indeed a place for me to reevaluate the changing trends of esports companies, as entities such as Blizzard and Riot have started to take notice to this prolific issue. And, while, I am unsure if this problem is near a resolution, with the continued proliferation of digital technologies, I am optimistic that it will be assuaged. However, this cannot be done unless both companies (in their history of passivity) and players come to understand that equality in gaming is not a problem which cannot be changed without engagement. Thus, I end this analysis with high spirits that it will provide even a small group with a deeper understanding of black identity in esports.

\section{References}

[1] Alvarado, Anne. 2010. "Dispelling the Meritocracy Myth: Lessons for Higher Education and Student Affairs Educators". The Vermont Collection Vol: 31.

[2] Boellstorff, Tom. 2019. "The Opportunity to Contribute: Disability and the Digital Entrepreneur." Information, Communication, \& Society 22 (4): 474-90.

[3] Brown, Wendy. "Undoing the Demos: Neoliberalisms Stealth Revolution." S.l.: ZONE BOOKS, 2017.

[4] Crenshaw, Kimberle. 1989. "Demarginalizing the Intersection of Race and Sex: A Black Feminist Critique of Antidiscrimination Doctrine, Feminist Theory, and
Antiracist Politics." Feminist Legal Theory, 2018, 57-80. https://doi.org/10.4324/9780429500480-5.

[5] Fanon, Fanon. 1952. "Black Skin, White Masks" New York: Grove Press.

[6] Fuchs, Christian. 2018. "Capitalism, Patriarchy, Slavery, and Racism in the Age of Digital Capitalism and Digital Labour." Critical Sociology 44 (4-5): 677-702

[7] Collins, Patricia Hill. "Learning From the outsider within: The sociological Significance of Black Feminist Thought." Oxford Press, Society for the Study of Social Problems.

[8] Gershon, Ilana. 2014. "Selling Your Self in the United States." Political \& Legal Anthropology Review 37 (2): 281-95.

[9] Gray, Kishonna L. 2018. "Gaming Out Online: Black Lesbian Identity Development and Community Building in Xbox Live.” Journal of Lesbian Studies 22 (3). Taylor \& Francis: 282-96.

[10] Hanson, Matt. 2018 "What It Takes to Become a Professional esports Player." TechRadar. June 14, 2018. https://www.techradar.com/news/what-it-takes-to-becomea-professional-esports-player.

[11] Higgin, Tanner. 2008. "Blackless Fantasy: The Disappearance of Race in Massively Multiplayer Online Role-Playing Games." Games \& Culture 4 (1): 3-26.

[12] Lawton, Anne. "The Meritocracy Myth and the Illusion of Equal Employment Opportunity." Minnesota Law Review, vol. 85, no. 2, December 2000, p. 587-662.

[13] McNamee, Stephen "The Meritocracy Myth". Rowman \& Littlefield Publishers. Kindle Edition.

[14] Peterson Latoya. 2018 "Why Aren't More Black Kids Going Pro in esports?" The Undefeated. March 28, 2018. https://theundefeated.com/features/why-arent-moreblack-kids-going-pro-in-esports/.

[15] Nakamura, Lisa. 2014. "Indigenous Circuits: Navajo Women and the Racialization of Early Electronic Manufacture.” American Quarterly 66 (4): 919-41.

[16] Spence, Lester K. 2015. "Knocking the Hustle: Against the Neoliberal Turn in Black Politics."

[17] Taylor, T. L. Raising the Stakes: esports and the Professionalization of Computer Gaming. Cambridge: MIT Press, 2015.

[18] Taylor, T. L. Watch Me Play: Twitch and the Rise of Game Live Streaming. Princeton, NJ: Princeton University Press, 2018.

[19] Wilson, William J. More than Just Race: Being Black and Poor in the Inner City. New York: Norton \& Company, 2010.

[20] Young, Harvey. Embodying Black Experience (Theater: Theory/Text/Performance). University of Michigan Press, 2010.

[21] Zwieganhaft L. Richard. 2003. "Has the Power Elite Gone Multicultural?." Reader for Race and Ethnicity: 177-184. 